\title{
A geomorphological approach to the estimation of landslide hazards and risks in Umbria, Central Italy
}

\author{
M. Cardinali ${ }^{1}$, P. Reichenbach ${ }^{1}$, F. Guzzetti ${ }^{1}$, F. Ardizzone ${ }^{1}$, G. Antonini ${ }^{2}$, M. Galli ${ }^{2}$, M. Cacciano ${ }^{3}$, M. Castellani ${ }^{3}$, \\ and P. Salvati ${ }^{3}$ \\ ${ }^{1}$ CNR - IRPI, via della Madonna Alta 126, 06128 Perugia, Italy \\ ${ }^{2}$ Terra s.n.c. Servizi al territorio, viale Vittorio Veneto 14/A, 06050 Papiano, Italy \\ ${ }^{3}$ Geologists, private consultants, Perugia, Italy
}

Received: 8 October 2001 - Accepted: 9 November 2001

\begin{abstract}
We present a geomorphological method to evaluate landslide hazard and risk. The method is based on the recognition of existing and past landslides, on the scrutiny of the local geological and morphological setting, and on the study of site-specific and historical information on past landslide events. For each study area a multi-temporal landslide inventory map has been prepared through the interpretation of various sets of stereoscopic aerial photographs taken over the period 1941-1999, field mapping carried out in the years 2000 and 2001, and the critical review of site-specific investigations completed to solve local instability problems. The multi-temporal landslide map portrays the distribution of the existing and past landslides and their observed changes over a period of about 60 years. Changes in the distribution and pattern of landslides allow one to infer the possible evolution of slopes, the most probable type of failures, and their expected frequency of occurrence and intensity. This information is used to evaluate landslide hazard, and to estimate the associated risk. The methodology is not straightforward and requires experienced geomorphologists, trained in the recognition and analysis of slope processes. Levels of landslide hazard and risk are expressed using an index that conveys, in a simple and compact format, information on the landslide frequency, the landslide intensity, and the likely damage caused by the expected failure. The methodology was tested in 79 towns, villages, and individual dwellings in the Umbria Region of central Italy.
\end{abstract}

Key words. Landslide, Hazard, Risk, Geomorphology, Inventory map, Umbria

\section{Introduction and background}

Much of Italy consists of hilly and mountainous terrain subject to landslides. Investigations aimed at assessing landslide risk in Italy have shown that in the last century landslides

Correspondence to: M. Cardinali

(m.cardinali@irpi.pg.cnr.it) affected at least 23600 sites. This is equivalent to a density (on average) of about one landslide per $10 \mathrm{~km}^{2}$. In the 20th century at least 7799 landslide casualties, and at least 100000 homeless or evacuated people were reported. Between 1990 and 1999 at least 263 people were killed by mass-movements, an average of 26 deaths per year (Guzzetti, 2000).

Damage and fatalities have been caused by single catastrophic failures and by widespread landsliding. The largest landslide catastrophe in Italy occurred at Vajont (Veneto Region), on 9 October 1963. At 18:30 h, 240 million cubic meters of rock detached from the western slopes of M. Toc and fell into the Vajont lake. The single rockslide pushed the water against the villages of Casso and Erto, and over the Vajont dam. A water wave overtopped the dam and destroyed the town of Longarone, killing at least 1917 people (Catenacci, 1992). Another highly destructive landslide occurred on 13 December 1982, at Ancona (Marche Region). The single slope failure involved the movement of 342 hectares of urban and suburban land, damage to two hospitals and the Faculty of Medicine at Ancona University, damage to or complete destruction of 280 buildings with a total of 865 apartments, displacement of the main railway and coastal road for more than $2.5 \mathrm{~km}$, one (indirect) death, and the evacuation of 3661 people (Crescenti, 1986; Catenacci, 1992). The economic loss was estimated at US\$700 million (Alexander, 1989).

Economic damage and fatalities are also caused by widespread shallow and deep-seated failures, triggered by intense or prolonged rainfall, by snowmelt, or by earthquakes. In the last decade events triggering thousands of landslides occurred in the Po Basin on 3-5 November 1994 (Regione Piemonte, 1998) and on 13-16 October 2000, causing 22 and 25 fatalities, respectively, and economic damage in excess of several million Euro. Other catastrophic events occurred on 19 June 1996 in Versilia (Tuscany Region, 14 casualties), and on 5-6 May 1998, at Sarno and Quindici (Campania Region), when secondary lahars detached from the slopes of Pizzo d'Alvano, killing 153 people.

The Sarno landslide disaster caused a tremendous impact 
nationwide, which included unprecedented coverage by the mass media. It prompted new legislation on landslide riskassessment procedures (Gazzetta Ufficiale della Repubblica Italiana, 1998). Under the aegis of this new legislation we have completed research aimed at assessing landslide hazard and risk in urban and rural areas of the Umbria Region.

\section{General setting}

The Region of Umbria covers $8456 \mathrm{~km}^{2}$ in central Italy (Fig. 1). The landscape is hilly or mountainous, with open valleys and intra-mountain basins, and elevation ranging from 50 to $2436 \mathrm{~m}$ a.s.l. The Tiber River, a tributary of the Tyrrhenian Sea, drains the area. Climate is Mediterranean, with distinct wet and dry seasons. Rainfall mainly occurs from October to February, with cumulative annual values ranging between 700 and $2000 \mathrm{~mm}$.

In Umbria four major groups of rock units crop out, namely: carbonate, flysch, volcanic rocks, and post-orogenic sediments (Fig. 1a). Each lithological complex comprises different rock types varying in strength from hard to weak and soft rocks. Hard rocks include layered and massive limestones, cherty limestones, sandstones, pyroclastic deposits, travertines and conglomerates. Weak rocks include marls, shales, sands, silty clays, and overconsolidated clays. Soft rocks are marine and continental clays, silty clays, and shales. Rocks are mostly layered, and structurally complex (Servizio Geologico d'Italia, 1980; Guzzetti et al., 1996; Cardinali et al., 2001).

In Umbria, unstable slopes were recognised and studied in many cities and towns, including Perugia, Orvieto, Assisi, Todi, Montone, and Allerona (Felicioni et al., 1994). Geomorphological investigations revealed that landslides cover about $14 \%$ of the entire land area. Landslide abundance and pattern vary largely within each lithological complex that is characterised by a prevalent geomorphological setting and by typical geotechnical and hydrogeological properties. Failures are largely controlled by the relative position of sedimentary and tectonic discontinuities, by the relative abundance of hard versus weak or soft rocks, and by the presence and attitude of permeable and impermeable layers (Guzzetti et al., 1996).

\section{Hazard and risk assessment project}

Following the catastrophic landslide disaster in Campania Region, on August 1998, the Italian Government passed new legislation on landslide and flood risk assessment and mitigation (Gazzetta Ufficiale della Repubblica Italiana, 1998). This requires that the Regional Governments and National River Basin Authorities identify and map areas where landslide risk is most severe, and take action to reduce economic damage and societal risk. The law was accompanied by a "technical document" providing a general framework and guidelines for the assessment of landslide hazard and risk (Gazzetta Ufficiale della Repubblica Italiana, 1999).
The Government of Umbria commissioned the CNR-IRPI Institute in Perugia to assess landslide hazard and risk in the Region. Due to the working scale of the project (set at 1:10000), and to economic and time constrains, not all the regional territory could be investigated fully. The Regional Geological Survey selected 79 places (towns, villages, individual houses, and road sections) to be investigated. The selection was guided by pre-existing information on slope failures, and on landslide events that caused damage. The exact location or the extent of the areas to be investigated was not given to us. For each site, we identified the extent of the study area, selected the landslides for which hazard was ascertained, and identified the vulnerable elements for which risk had to be estimated.

\section{Hazard and risk assessment strategy}

Assessing landslide hazard and risk is a complex operation that requires the combination of different techniques and methodologies, and the interplay of various expertises, not all of which pertain to the realm of the earth sciences (Hungr, 1997). A review of the vast literature on landslide hazard assessment (see: Varnes and IAEG, 1984; Hutchinson, 1995; Guzzetti et al., 1999; and references herein), and of the smaller literature on landslide risk assessment (Einstein, 1988, 1997; Fell, 1994, 2000; Cruden and Fell, 1997) is not within our scope. In this section we briefly review the concepts and terminology related to landslide hazard and risk assessment, and we present a new geomorphological methodology to evaluate landslide hazard and to estimate landslide risk. For explanation purposes we use the village of Rotecastello in the San Venanzo Municipality, one of the 79 Umbrian localities where landslide hazard and risk were ascertained (Figs. 1b and 2).

\section{Concepts and terminology}

Landslide hazard refers to the natural conditions of an area potentially subject to slope movements. It is defined as the probability of occurrence of a landslide of a given magnitude, in a pre-defined period of time, and in a given area (Varnes and IAEG, 1984). The definition incorporates the concepts of spatial location ("where"), magnitude or intensity ("how large"), and frequency of occurrence ("when", or "how often"). Location refers to the ability to forecast where a landslide will occur; magnitude refers to the prediction of the size and velocity of the landslide; and frequency refers to the ability to forecast the temporal recurrence of the landslide event (Guzzetti et al., 1999). Ideally, a landslide hazard map will portray the location and probability of occurrence of mass movements of pre-defined or design magnitudes in the study area (Carrara et al., 1995, 1999; Guzzetti et al., 1999).

Landslide risk expresses the economic and social dimension of slope failure. It is generally considered to be equal to the likelihood of death or injury, or to the expected monetary loss due to the occurrence of a landslide (Varnes and IAEG, 


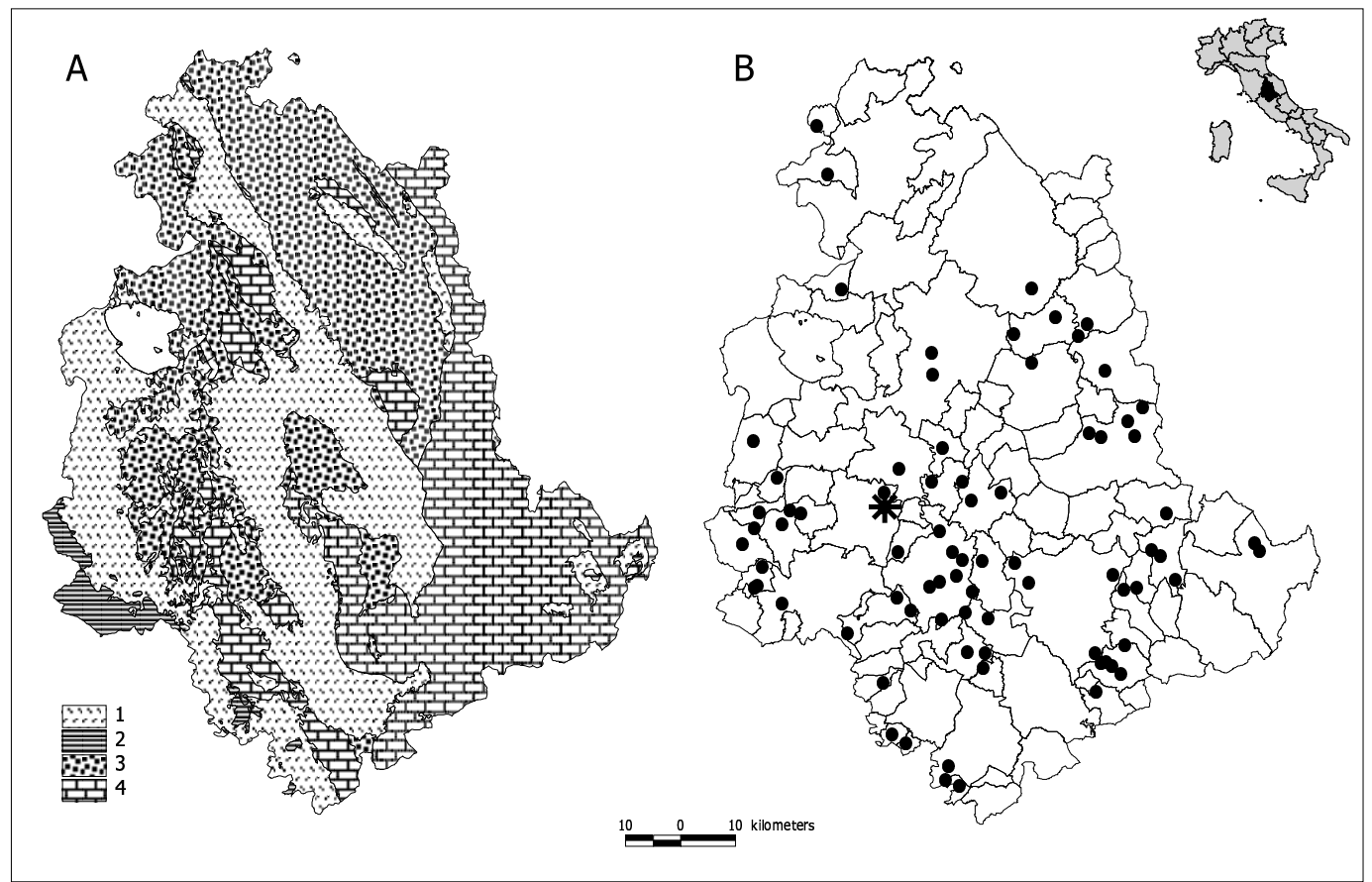

Fig. 1. Umbria Region. Index map and location of the study area. (a) Rock units appearing in the Umbria Region. Map Legend: 1) Postorogenic marine and continental sediments. 2) Volcanic rocks. 3) Flysch deposits; 4) Limestone and marl sediments. (b) Location of the 79 towns, villages and single dwellings where landslide hazard and risk were identified. The asterisk shows the location of Rotecastello village, in San Venanzo Municipality, Terni Province.

1984; Einstein, 1988, 1997; Michael-Leiba et al., 1999; Fell, 1994, 2000; Fell and Hartford, 1997). Landside risk is usually defined as the product of landslide hazard and vulnerability. The latter ranges from 0 , meaning no damage, to 1 , representing complete destruction. The definition of landslide risk requires that both hazard and vulnerability be defined as independent probabilities (of occurrence, for hazard; and of damage, for vulnerability). In practice, it is rarely possible to define hazard and vulnerability as probabilities, which reduces the limits of rigour for applying the definition of landslide risk.

Due to the highly variable destructiveness of landslides, and their extremely changeable characteristics (i.e. size, shape, velocity and momentum), vulnerability is difficult to define precisely. Ideally, a vulnerability assessment should include considerations of the type of failure (e.g. size, shape, volume and velocity), the elements at risk (e.g. type, size, construction characteristics and maintenance status), and of a building's ability to survive the expected landslide. This is not an easy task, as it requires the study of past landslides that have caused damage, as well as needing critical interpretation. The evaluation of the vulnerability of an element at risk is further complicated by the fact that the same element may respond well to a certain type of failure, and perform poorly in a different type of landslide. As an example, a road may be slightly damaged by a rock fall but completely destroyed by a slow moving, deep-seated slump. To complicate matters further, a person travelling along the same road exhibits a high vulnerability to rock falls (the person is likely to be killed if hit by a rock), but has a comparatively low vulnerability to the slow-moving slump.

\section{The methodology}

We assessed landslide hazard and risk using a geomorphological approach, combined with the analysis of site-specific and historical information where this was available. We started with the careful scrutiny and mapping of the "state of nature", i.e. of all the existing and past landslides that could be identified in the study area. Based on the observed changes in the distribution and pattern of landslides, we inferred the possible evolution of slopes, the probable shortterm types of failure and their expected frequency of occurrence. We used this information to estimate the landslide hazard and to evaluate the landslide risk.

More precisely, the methodology involved the following steps:

- Definition of the extent of the study area;

- Production of a multi-temporal landslide inventory map, including a landslide classification;

- Definition of landslide hazard zones around existing single or multiple landslides;

- Landslide hazard assessment; 


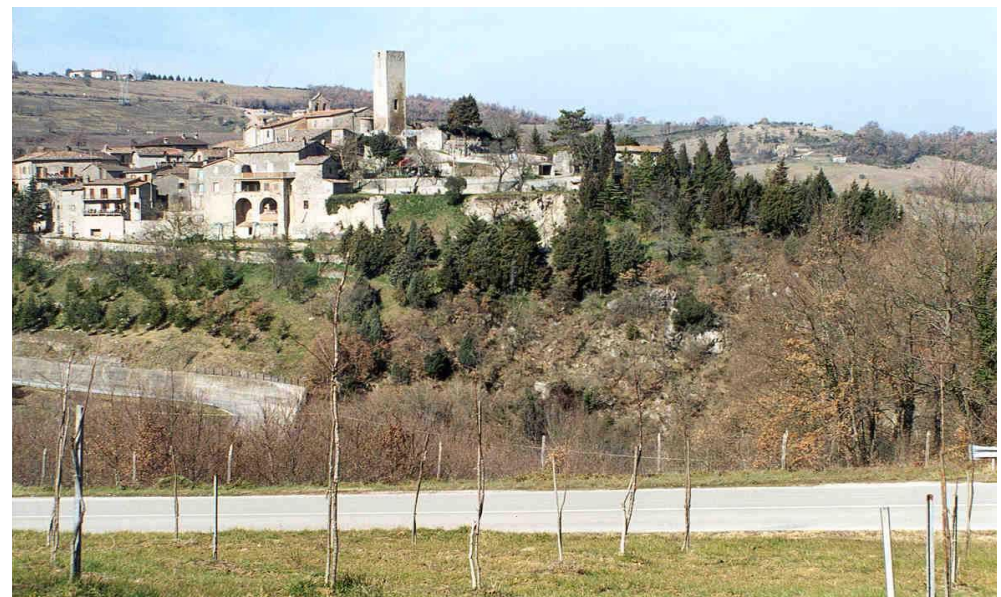

Fig. 2. General view of the western side of the village of Rotecastello, in central Umbria.
- Identification and mapping of the elements at risk, and assessment of their vulnerability to different landslide types;

- Evaluation of landslide risk.

\section{The study area}

First, the study areas had to be defined. This involved identifying the location and extent of each area to be investigated (i.e. the "site"). This was not a trivial problem, because sites in different lithological and morphological domains had to be identified using the same criteria.

We defined a "site" as an area bounded by drainage channels or interfluves around one of the places selected for investigation by the Regional Government. A site is an ensemble of one or more adjacent watersheds or "elementary slopes", i.e. areas bounded by channels and interfluves. Wherever possible major divides and drainage lines were selected. Where this was not feasible minor divides or drainage channels were used. Selection of a geomorphological unit as the study area is justified by the observation that landslides occur mostly along the slope crests in the Umbria Region.

Mapping of elementary slopes or sub-watersheds was accomplished at 1:10000 scale, using the available large-scale topographic maps (CTR, 1:10000 scale), locally aided by the analysis of large- and medium-scale aerial photographs (see Table 1). At each site, the number and the extent of the elementary slopes depended on the local geological and morphological setting, and on the type, number and extent of landslides. The number of elementary slopes ranged from one to seven, and their area ranged from 0.1 to $4 \mathrm{~km}^{2}$.

\section{Multi-temporal landslide inventory map}

In Umbria landslides show a remarkable spatial recurrence (Cardinali et al., 2000). Landslides tend to occur (in time and in space), within or in the vicinity of other landslides, or in the same slope or watershed. This suggests that knowledge of the location of past failures is the key to forecasting the future occurrence of landslides in the Region.

Within each study area we ascertained the spatial distribution of landslides through the interpretation of multiple sets of stereoscopic aerial photographs, and by carrying out detailed field surveys in the years 2000 and 2001. Table 1 lists the characteristics of the aerial photographs that were used. Ten sets of photographs taken in different years were available for the period 1941-1999. The nominal scale of these photographs ranged from 1:13000 (Regione Umbria, 1977) to $1: 73000$ (Volo Italia, 1994). Only the GAI (1954-1955), the Regione Umbria (1977) and the Volo Italia (1994) flights cover the entire area. For the Rotecastello site flights A, B, $\mathrm{C}$, and $\mathrm{H}$ of Table 1 were used.

We started by identifying landslides on the 1954-1955 aerial photographs. Besides covering the entire region at a scale (1:33 000) suitable for the identification of landslides, this flight took place before the intensive post-war agricultural exploitation of the area. In the photographs landslides are clearly identifiable because they were not obliterated by ploughing or other farming activities (Guzzetti and Cardinali, 1989). For the Rotecastello site, Figure 3a shows the inventory map prepared by interpreting the September 1954 aerial photographs at the 1:33000 scale. The map portrays all the landslides that were identified, regardless of the estimated age. Very old (relict) deep-seated landslides are shown together with old and recent (in 1954) surficial and deep-seated landslides. For the deep-seated landslides the crown area and the deposits were mapped separately.

We then analysed the other sets of aerial photographs, separately and in conjunction with the 1954-1955 flight, and we prepared separate landslide inventory maps (Figs. 3ae). The map of Fig. $3 \mathrm{~b}$ portrays the landslides that looked "fresh" (i.e. new or active) in the 1941 photographs. These landslides were probably triggered by a large meteorological event that occurred in November 1937 in the Tiber basin. Figure $3 \mathrm{c}$ shows all new or active landslides identified in the 1977 photographs. These landslides were not shown on the older photographs. An attempt (not shown in Fig. 3c) 

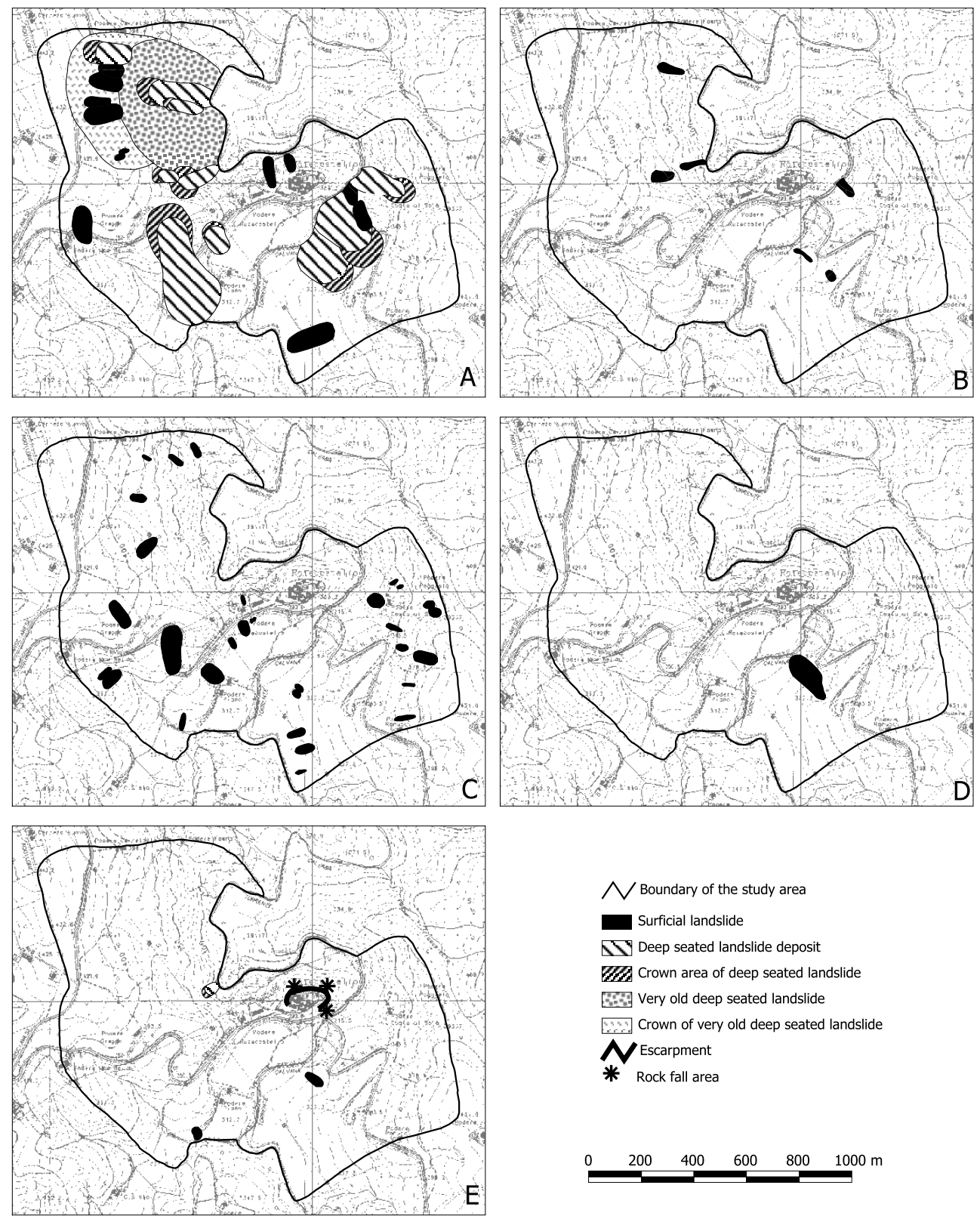

Fig. 3. Rotecastello, central Umbria. Landslide inventory maps. (a) Landslides identified on the September 1954 aerial photographs. (b) Active and new landslides identified on the 1941 aerial photographs. (c) Active and new landslides identified on the 1977 aerial photographs. (d) Active and new landslides identified on the 1997a aerial photographs. (e) Active and new landslides identified during the fieldwork completed in 2000 and 2001. Rock falls, of unknown age, were identified in the field.

was made to distinguish landslides that were "fresh" in 1977 (i.e. active landslides or failures that had occurred a few months or years before the photographs were taken) from the other, slightly older landslides that occurred after 1954. Figure 3d shows new landslides mapped on the 1997 aerial photographs at the 1:20000 scale, and triggered by the rapid melting of snow cover in January 1997 (Cardinali et al., 2000). Lastly, Fig. 3e shows new and active slope failures mapped during the field campaign of 2000-2001. These landslides occurred in the previous autumn and winter seasons. Figure $3 \mathrm{e}$ also shows the location of rock falls identi- fied in the field, which are of an unknown age.

Landslide information collected through the interpretation of aerial photographs or mapped in the field was transferred on large-scale topographic maps (at 1:10000 scale) or, where these were not available, on ortophoto maps at the same scale. The five landslide maps (Fig. 3) were then combined to obtain a multi-temporal landslide inventory map, as shown in Fig. 4. This was accomplished by overlaying the separate maps, and merging them into a single map. The process required some adjustments to eliminate minor positional and drafting errors. The multi-temporal landslide inventory map 
Table 1. Characteristics of the stereoscopic aerial photographs used to prepare the landslide inventory and multi-temporal landslide maps

\begin{tabular}{|c|c|c|c|c|c|c|c|}
\hline & Flight name & Scale & Type & Year & Season & Coverage & Notes \\
\hline A & IGM & $1: 20000$ & $\mathrm{~B} \& \mathrm{~W}$ & 1941 & - & Portions of the region & Flown during the \\
\hline B & GAI, IGM & $1: 33000$ & $\mathrm{~B} \& \mathrm{~W}$ & 1954-1955 & Various & Entire region & $\begin{array}{l}\text { Second World War } \\
\text { September } 1954 \text { in } \\
\text { the Rotecastello area }\end{array}$ \\
\hline $\mathrm{C}$ & Regione Umbria & $1: 13000$ & Colour & 1977 & Spring & Entire region & \\
\hline $\mathrm{D}$ & IGM & $1: 36000$ & $\mathrm{~B} \& \mathrm{~W}$ & 1991 & September & Northern Umbria & \\
\hline $\mathrm{E}$ & IGM & $1: 36000$ & $\mathrm{~B} \& \mathrm{~W}$ & 1993 & July & South western Umbria & \\
\hline $\mathrm{F}$ & IGM & $1: 36000$ & $\mathrm{~B} \& \mathrm{~W}$ & $1994 \mathrm{a}$ & March & South eastern Umbria & \\
\hline G & Volo Italia & $1: 73000$ & $\mathrm{~B} \& \mathrm{~W}$ & $1994 \mathrm{~b}$ & September & Entire region & High altitude flight \\
\hline $\mathrm{H}$ & IRPI & $1: 20000$ & $\mathrm{~B} \& \mathrm{~W}$ & 1997 a & Spring & Central Umbria & $\begin{array}{c}\text { Flown after the snow-melting } \\
\text { event of January } 1997\end{array}$ \\
\hline I & DPC & $1: 13000$ & $\mathrm{~B} \& \mathrm{~W}$ & $1997 \mathrm{~b}$ & Fall-Winter & Eastern Umbria & $\begin{array}{c}\text { Flown after the } \\
\text { September } 1997 \text { earthquakes }\end{array}$ \\
\hline $\mathbf{J}$ & Regione Umbria & $1: 28000$ & $\mathrm{~B} \& \mathrm{~W}$ & 1999 & October & Southern Umbria & \\
\hline
\end{tabular}

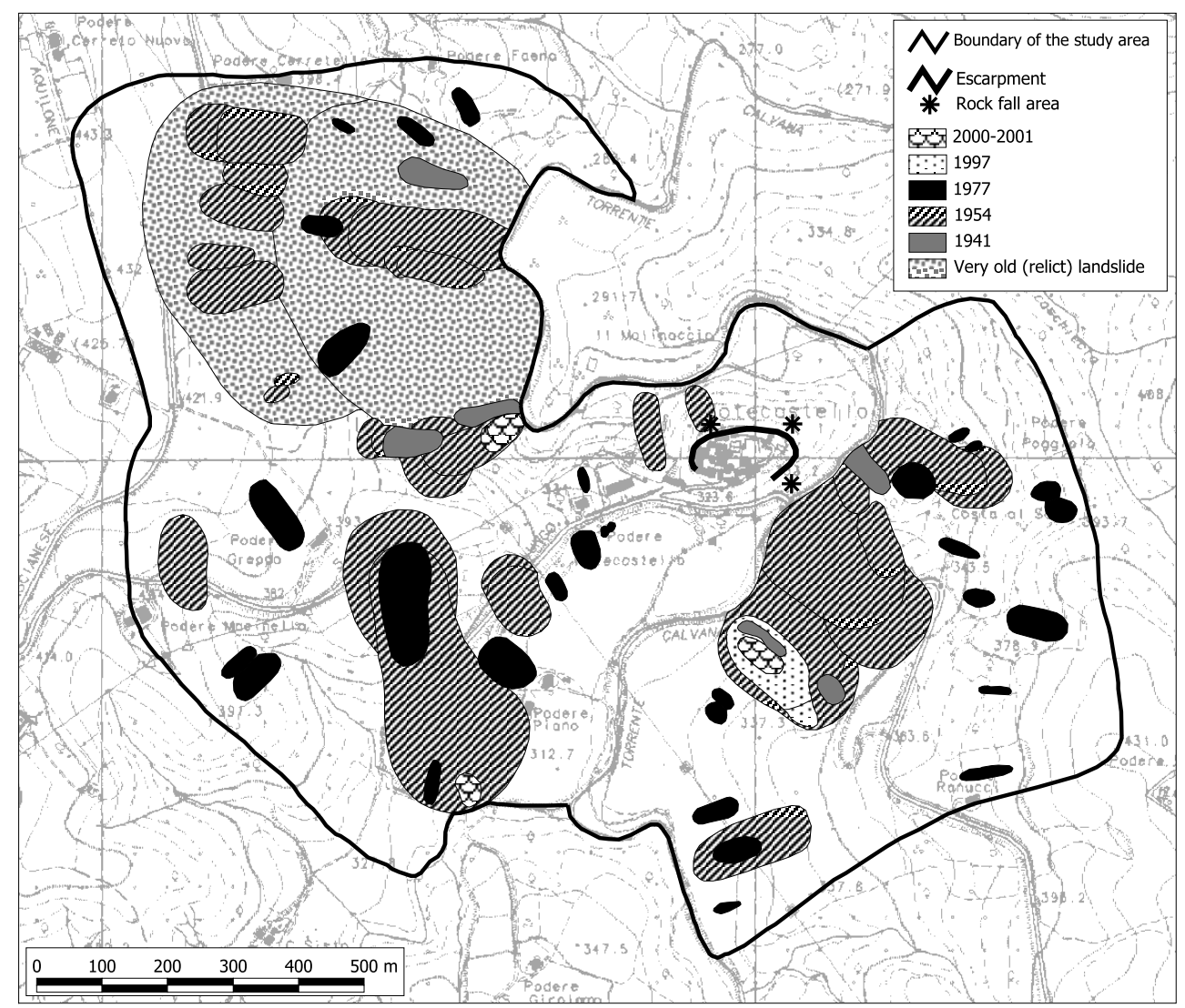

Fig. 4. Rotecastello, central Umbria. Multi-temporal landslide inventory map. Numbers in the legend refer to the year of the flights used to identify the landslides (see Table 1).

was then digitised and stored in a GIS for analysis and display.

\section{Landslide classification}

Landslides were classified according to their type of movement, and their estimated ages, degrees of activity, depths, and velocities. The level of certainty in the recognition of the landslide was also noted. Landslide type was defined according to the classifications of Varnes (1978), Cruden and Varnes (1996), and the WP/WLI (1990, 1993, 1995). Landslide age, activity, depth, and velocity were ascertained according to the type of movement, the morphological characteristics and appearance of the landslide, the local lithological and structural settings, and, where available, the results 
of site-specific investigations carried out to solve local instability problems.

The relative age of a landslide was defined as recent, old or very old. Landslides of recent age were recognised according to the following categories: morphologically fresh (i.e. "active") on the aerial photographs taken in 1941 and 1954-1955; new landslides or reactivations of pre-existing landslides in the more recent aerial photographs $(1977,1991$, 1993, 1997); or by field mapping carried out in 2000 and 2001. Old landslides were recognised on the 1954-1955 aerial photographs, but these features did not exhibit any detectable morphological change of the (entire) original feature in the more recent aerial photographs or during the field surveys. Very old landslides were identified on the 19541955 aerial photographs, and were regarded as those that showed a relict morphology largely dismantled by erosion. They mostly involved large volumes of rock or sediment, and probably occurred in different climatic or seismic conditions (Guzzetti et al., 1996).

The evaluation of landslide activity requires detailed information on the movement of the landslide (WP/WLI, 1993; 1995). This implies inevitably that some device or system capable of measuring displacement (e.g. inclinometer, extensiometer or topographic survey) is available. Given the scale of the investigation, the extent and number of landslides in each study area, and the lack of quantitative measurements, landslide activity was ascertained mostly on a geomorphological base; i.e. landslides were classified as active where they looked fresh on the aerial photographs, or where movement was known from monitoring systems.

Landslides were classified as deep-seated or shallow, depending on the type of movement and the landslide volume. Evaluation of landslide volume was based on the type of failure, and the morphology and geometry of the detachment area and deposition zone.

Landslide velocity was considered as a proxy for landslide type, and was classified accordingly (WP/WLI, 1995). Rotational or translative slides, earth-flow slides, flows, and complex or compound slides were classified as slow moving failures. Debris flows were classified as rapid movements. Rock falls, including topples, were classified as fast moving landslides.

We acknowledge that landslide classification, and in particular, the evaluation of landslide age, activity, velocity and depth, includes simplifications. The classification required geomorphological inference on our side, but it does fit the available information on landslide types and process in Umbria (Felicioni et al., 1994; Guzzetti et al., 1996; Alexander, 2000).

\section{Landslide frequency}

To assess hazard, information on landslide frequency is needed. Frequency refers to the temporal occurrence of landslides and can be obtained through the analysis of historical data (Guzzetti et al., 1999). In general, a complete (or at least systematic) record of past landslides from which to derive their frequency of occurrence is difficult to obtain for a single landslide, slope, or small watershed (Ibsen and Brunsden, 1996; Glade, 1998; Guzzetti et al., 1999). Guzzetti et al. (1999) argued that evidence of past movements on a slope might not necessarily indicate the possibility of future landslides.

Due to a lack of information on the temporal occurrence of landslides for most of the investigated sites, we ascertained landslide frequency based on the analysis of the multitemporal inventory map, which covers an observation period of 60 years. We ascertained the frequency of occurrence of single or multiple landslides, based on the number of events (i.e. the localized morphological changes) recognised during this observation period. For convenience, four classes of landslide frequency were identified:

- Low frequency (1), when only one landslide event was observed;

- Medium frequency (2), when 2 events were observed;

- High frequency (3), when 3 events were observed; and

- Very high frequency (4), when more than 3 events were observed in 60 years.

No distinction was made between the date of occurrence of slope failures inferred through the interpretation of aerial photographs or known from field instrumentation or technical reports. A site where a landslide was only recognised in 1954-1955 and one where a landslide was identified only on the 1997 aerial photographs were both assigned a low frequency. Similarly, a site where landslides were observed in 1941, 1954-1955, 1977 and in 2001 (i.e. 4 times in 60 years), and a site where landslides were identified in 1977 , 1994, 1997, and 2000 (i.e. 4 times in 24 years), were assigned the same (very high) frequency. A further complication or added uncertainty arose because the landslide dates inferred from the multi-temporal inventory map had different temporal constrains. A landslide identified on the aerial photographs taken immediately after an event (i.e. 1997a, 1997b), or not too far after it (i.e. 1941), provided a closer estimate on the date of movement than a landslide identified on the other flights, taken decades (or even centuries for the very old landslides) after the slope failures.

\section{Landslide intensity}

The definition of hazard requires information on landslide intensity. Contrarily to other natural hazards, such as earthquakes or volcanic eruptions, no unique or commonly recognised measure of landslide intensity is available (Hungr, 1997). Since our goal was to estimate landslide risk, we considered landslide intensity $(I)$ as a measure of the destructiveness of the landslide (Hungr, 1997), and we defined it as a function of the landslide volume $(v)$ and of the landslide 


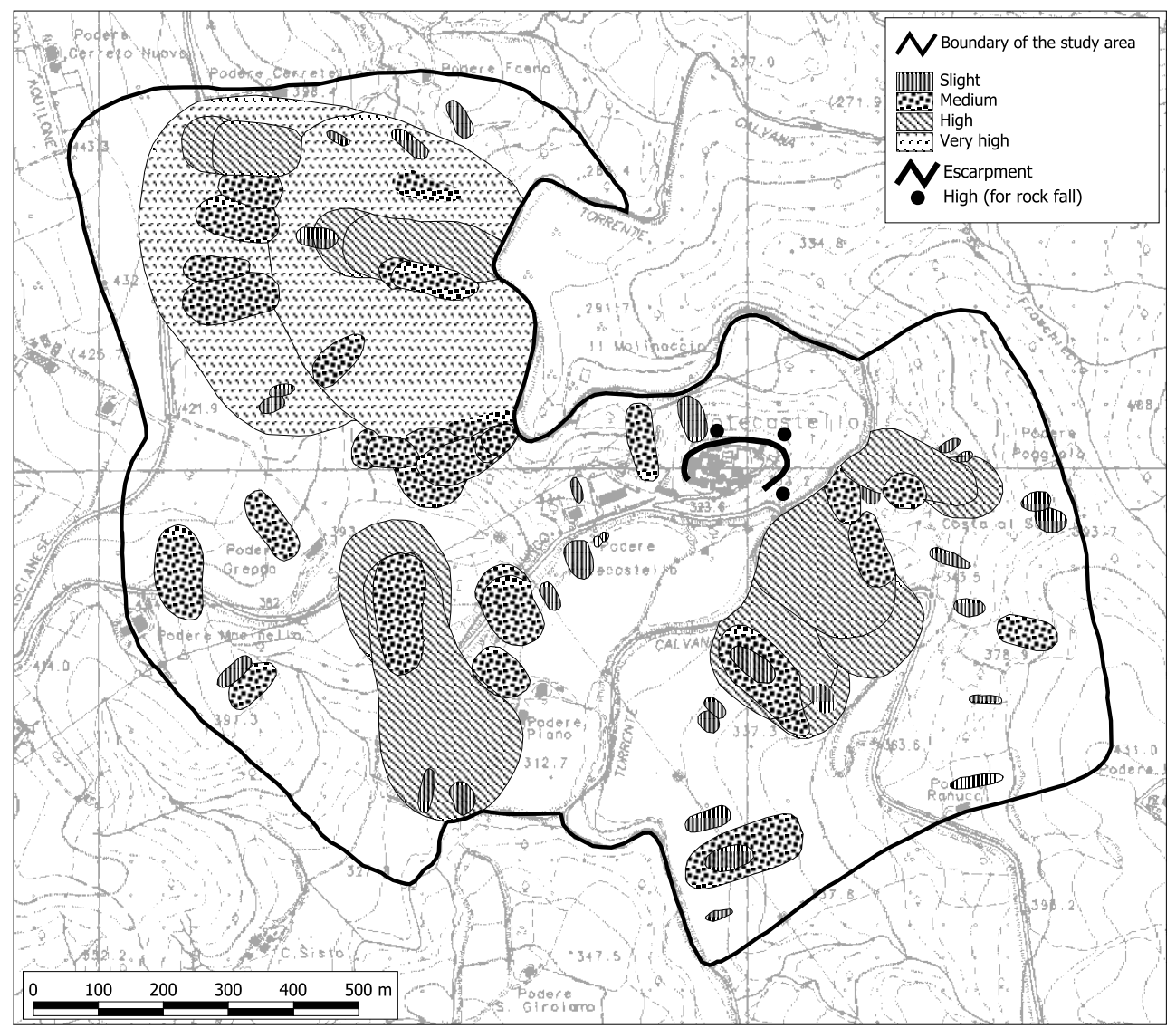

Fig. 5. Rotecastello, central Umbria. Map showing the expected landslide intensity (see Table 2). Landslides were also classified on the basis of estimated age, degree of activity, depth of movement and velocity (not shown here). Rock falls, shown by asterisks, were assigned high landslide intensities.

Table 2. Landslide intensity, grouped into four classes: light (1), medium (2), high (3) and very high (4). Note that landslide intensity varies with the landslide type

\begin{tabular}{c|ccc}
\hline $\begin{array}{c}\text { Estimated volume } \\
\left(\mathrm{m}^{3}\right)\end{array}$ & $\begin{array}{c}\mid c \\
\text { Expected landslide velocity } \\
\text { Rast moving landslide } \\
\text { (Rock fall) }\end{array}$ & $\begin{array}{c}\text { Rapid moving landslide } \\
\text { (Debris flow) }\end{array}$ & $\begin{array}{c}\text { Slow moving landslide } \\
\text { (Slide) }\end{array}$ \\
\hline$<0.001$ & Slight (1) & & \\
$<0.5$ & Medium (2) & & \\
$>0.5$ & High (3) & Slight (1) & Slight (1) \\
$<500$ & High (3) & Medium (2) & Medium (2) \\
$500-10000$ & High (3) & High (3) & High (3) \\
$10000-50000$ & Very High (4) & Very High (4) & Very High (4) \\
$>500000$ & & &
\end{tabular}

expected velocity $(s)$

$I=f(v, s)$.

Table 2 shows how we assigned the intensity to each landslide (or group of landslides) based on the estimated volume and the expected velocity. We estimated volume on the basis of landslide type. For slow-moving slides, volume depended on the estimated depth of movements; for rapid moving debris flows it depended on the size of the catchment and the es- timated volume of debris in source areas and along channels; while for fast-moving rock falls it depended on the maximum size of a single block as estimated from field observations. The expected landslide velocity depends on the type of failure, its volume and the estimated depth of movement. For a given landslide volume, fast moving rock falls have the highest landslide intensity, while rapidly moving debris flows exhibit intermediate intensity, and slow moving landslides have the lowest intensity. 
Figure 5 shows the distribution of expected landslide intensity for the Rotecastello site.

\section{Landslide hazard zones}

The evaluation of landslide hazard can be carried out regionally or locally. The first involves assessing landslide hazard for an entire area, such as a river basin, a municipality or a province; the latter involves assessing the hazard of a single landslide, or a group of landslides (Carrara et al., 1995, 1999; Hutchinson, 1995; Guzzetti et al., 1999). Making a compromise, we decided to evaluate landslide hazard only in the areas of evolution of existing (mapped) landslides. For this purpose, a "landslide hazard zone" (LHZ) is defined as the area of possible (or probable) short-term evolution of an existing landslide, or a group of landslides, of similar characteristics (i.e. of type, volume, depth, and velocity), identified from the aerial photographs or observed in the field. A LHZ is therefore a "landslide scenario", delimited using geomorphological criteria.

To identify and map the extent of LHZs we used the multitemporal landslide inventory map. Based on the observed location, distribution and pattern of landslides, their observed or inferred style of movement and activity, and the local lithological and morphological setting, we mapped the area of possible evolution of each landslide, or group of landslides within each elementary slope. To define the LHZs, we considered the observed partial or total reactivation of existing landslides; the lateral, head (retrogressive) or toe (progressive) expansion of the existing landslides; and the possible occurrence of new landslides of similar type and intensity.

We identified different landslide scenarios (i.e. different LHZ) for each type of failure observed on an elementary slope (e.g. fast-moving rock falls, rapid-moving debris flows, slow-moving earth-flow slumps or compound failures). An LHZ includes the area currently recognised as a landslide (i.e. the crown and the deposit), and the area of possible direct or indirect influence of the observed phenomenon. For slow-moving failures, such as slides, slumps, earth-flows or compound failures, the LHZ is generally limited to the immediate surroundings of the existing landslide, or group of landslides (cf. Fig. 6c). This is justified by the fact that in Umbria the evolution of these types of landslides is relatively slow and spatially predictable (Cardinali et al., 2000). For relict (i.e. very old) landslides, most probably triggered in different morphological, climatic or seismic conditions (Guzzetti et al., 1996), the LHZ coincided with the entire slope element (cf. Fig. 6a). For debris flows the LHZ encompassed the source areas, the river channels and the depositional areas (alluvial or debris fans). For rock falls, topples, and minor rockslides, the LHZ included the escarpments from where landslides detached, and the talus, debris cones, and debris slopes along which rock falls travelled and where they eventually stopped (cf. Fig. 6d).
Table 3. Landslide hazard for each LHZ: Landslide intensity, grouped into four classes: light (1), medium (2), high (3) and very high (4), and the estimated landslide frequency, grouped into four classes: low (1), medium (2), high (3) and very high (4)

\begin{tabular}{l|cccc}
\hline \multirow{2}{*}{$\begin{array}{l}\text { Estimated landslide } \\
\text { frequency }\end{array}$} & Light & Medium & High & Very high \\
\hline Low (1) & $(1)$ & $(2)$ & $(3)$ & $(4)$ \\
Medium (2) & 11 & 12 & 13 & 14 \\
High (3) & 21 & 22 & 23 & 24 \\
Very high (4) & 31 & 32 & 33 & 34 \\
\hline
\end{tabular}

\section{Hazard assessment}

Landslide hazard $(H)$ depends on the frequency of landslide movements $(F)$ and on the landslide's intensity $(I)$,

$H=f(F, I)$.

Table 3 shows how we defined landslide hazard for each LHZ, combining frequency and intensity. Landslide frequency was estimated using four classes, based on the number of landslide events (of the same type) observed within each LHZ. Landslide intensity was defined in four classes, based on the estimated volume and the expected velocity. Figure 6 shows the hazard at the Rotecastello site for the different types of failures: very old (relict), deep-seated landslides (Fig. 6a); old and recent, deep-seated landslides (Fig. 6b); shallow, mostly recent, landslides (Fig. 6c); and rock falls (Fig. 6d).

Levels of landslide hazard in Table 3 are shown using a two-digit positional index. The right digit shows the landslide intensity $(I)$ and the left digit shows the estimated landslide frequency $(F)$. The index expresses landslide hazard by keeping the two components of the hazard distinct from one another. This facilitates landslide hazard zoning by allowing a user to understand whether the hazard is due to a high frequency of landslides (i.e. high recurrence), a large intensity (i.e. large volume and high velocity), or both.

It is worth noting that values of the landslide hazard index shown in Table 3 do not provide an absolute ranking of hazard levels. If the extreme values are easily defined, intermediate conditions of landslide hazard are more difficult to rank. A landslide that exhibits low frequency and light intensity $(H=11)$ will certainly have a much lower hazard than one that exhibits very high frequency and intensity $(H=44)$. Deciding whether the hazard of a landslide with very high frequency and light intensity $(H=41)$ is higher (or lower) than that of a landslide with low frequency and very high intensity $(H=14)$ is not straightforward and may be a matter of opinion.

\section{Elements at risk and their vulnerability}

We had no access to any map of the elements at risk (e.g. houses, buildings, roads, railways, utilities and population) 

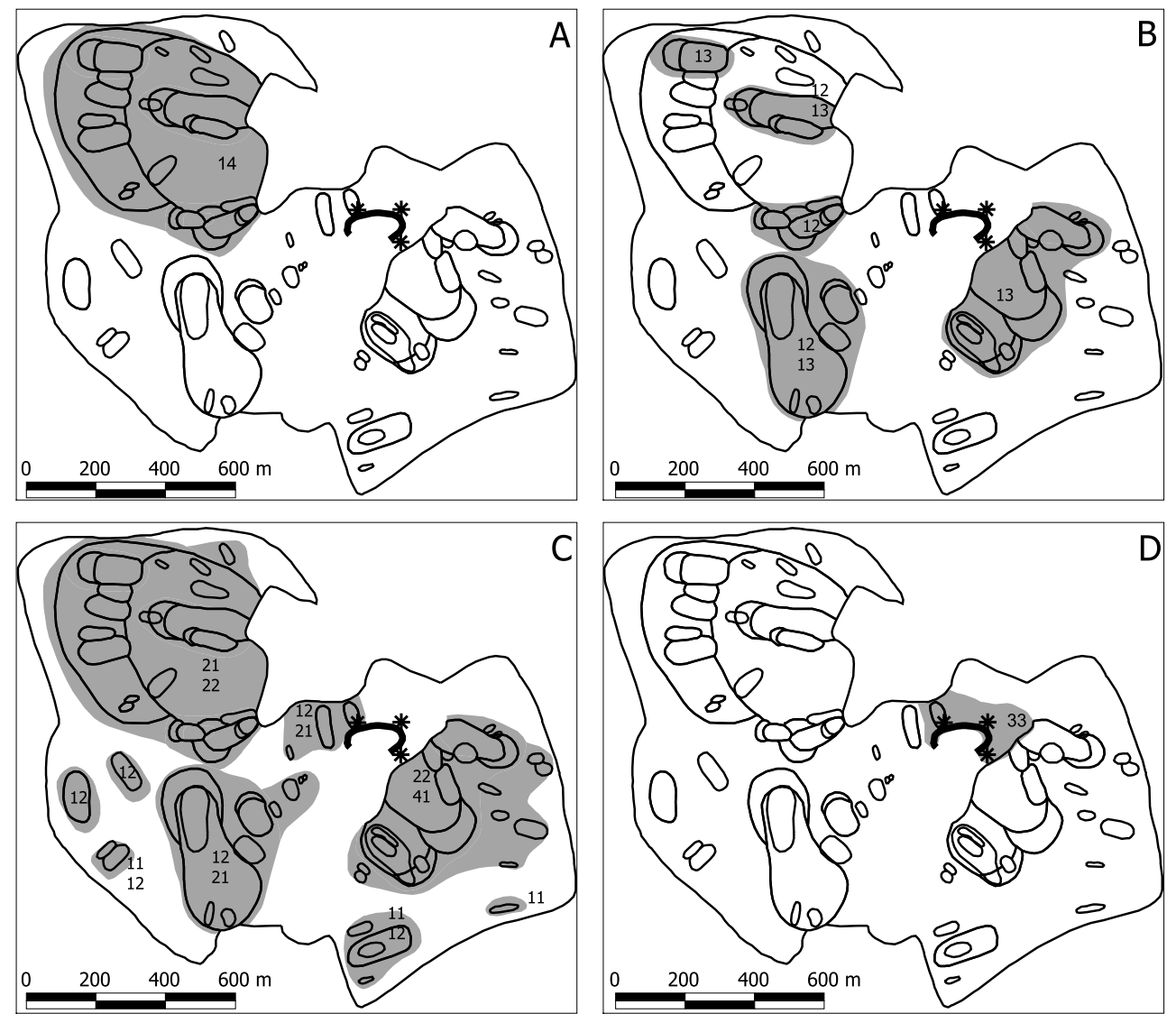

Fig. 6. Rotecastello, central Umbria. Maps of landslide hazard zones (LHZ, grey pattern) and of landslide hazard. (a) LHZ for very old (relict) slow moving, deep-seated landslide. (b) LHZ for old and recent, slow moving, deep-seated slides. (c) LHZ for slow-moving, surficial landslides. (d) LHZ for fast moving rock falls. Landslide hazard is shown using a two-digit index. Where two values are given (e.g. (b) or (c)) landslides of the same type but of different intensity or frequency are present.

Table 4. Types of element at risk (for structures and infrastructures)

\begin{tabular}{ll}
\hline Code & Frequency \\
\hline HD & Built-up areas with high population density \\
LD & $\begin{array}{l}\text { Built-up areas with low population density } \\
\text { and scattered houses }\end{array}$ \\
IN & Industries \\
FA & Animal farms \\
SP & Sports facilities \\
Q & Quarries \\
MR & Main roads, motorways, highways \\
SR & Secondary roads \\
FR & Farm and minor roads \\
RW & Railway lines \\
C & Cemeteries
\end{tabular}

at an appropriate scale and with sufficient detail and accuracy. For each study area we prepared a map of the elements at risk at the 1:10000 scale based on information on built-up areas, structures and infrastructures present on large-scale topographic maps (CTR at 1:10000 scale), aided by the recent aerial photographs (Fig. 7). Care was taken in locating the elements at risk inside or in the vicinity of the landslides or in potentially dangerous areas. The map was then digitised and stored in a GIS for analysis and display.

Elements at risk were classified according to a simple legend, as shown in Table 4. Of the eleven classes present in the legend, six referred to built-up areas and structures (i.e. houses, buildings, industry and farms, sport utility, cemetery); four to transportation utilities (roads and railways); and one to mining activities (a quarry). Built-up areas included public streets, roads, squares and gardens.

No information was available to us on the amount (or density) of the population in the study areas. To estimate the landslide risk to the population we considered the houses, buildings and roads as a proxy for the population density. In other words, we considered the population to be vulnerable in conjunction with (or because of) the presence of structures and infrastructures. As an example, vulnerability of the population was considered higher along a high transit road than along a secondary road. For sparse, farming structures, it was considered lower than in a densely populated zone.

As previously discussed, evaluating the expected damage to each element at risk is a difficult and uncertain operation. 


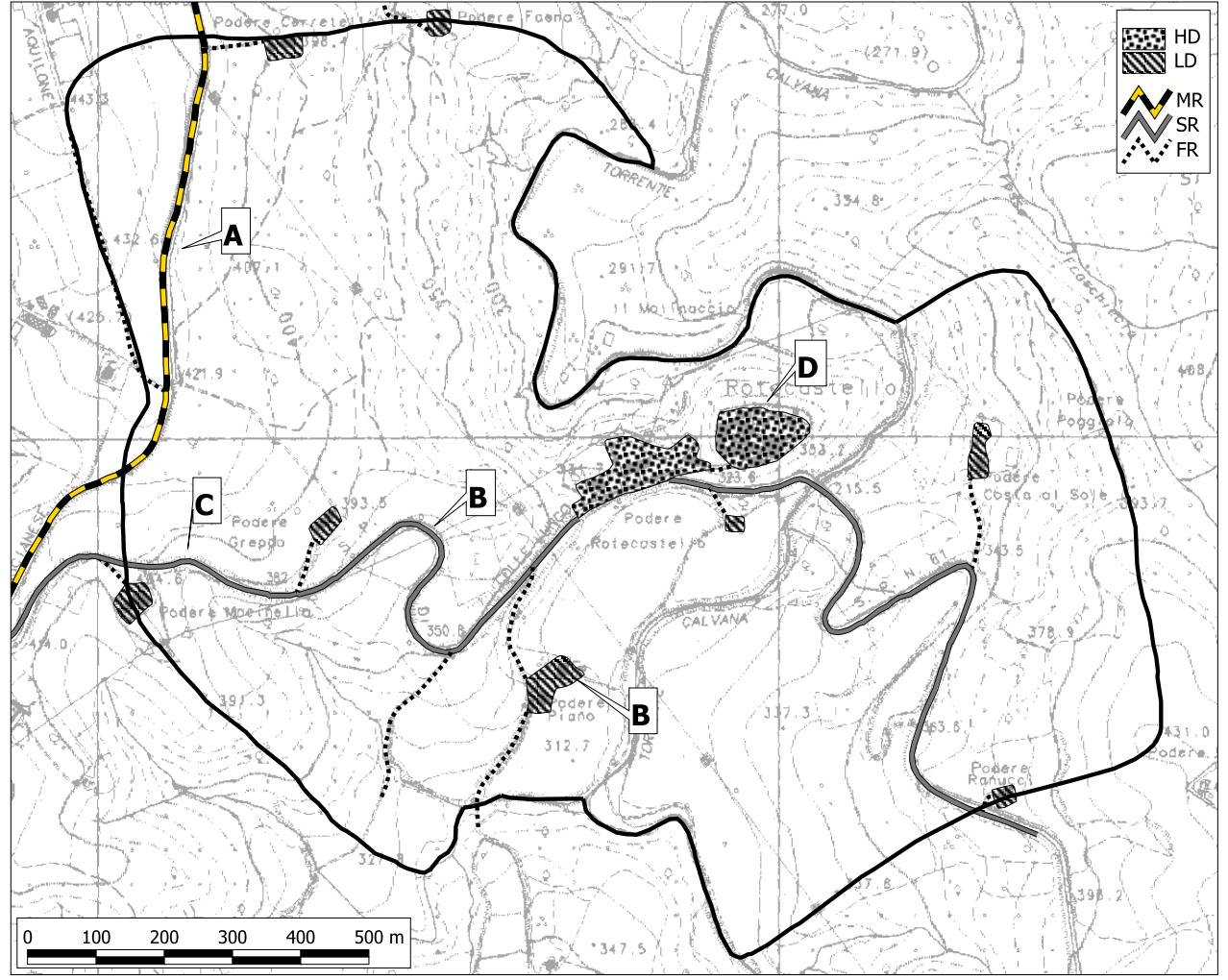

Fig. 7. Rotecastello, central Umbria. Map of the elements at risk. Legend (see Table 4): HD, built-up areas with a high population density; LD, built-up areas with a low population density and scattered houses; MR, main road; SR, secondary road; FR, farm road. Letters indicate the location of elements at risk in Figs. 8a-d.

Table 5. Vulnerability, the expected damage to the elements at risk. A = superficial (aesthetical, minor) damage; $F=$ functional (or medium) damage; $S=$ structural (or total) damage. For classes of elements at risk see Table 4 . For landslide intensity see Table 2

\begin{tabular}{|c|c|c|c|c|c|c|c|c|c|c|c|c|c|c|c|}
\hline \multicolumn{2}{|c|}{ Landslide Intensity } & \multicolumn{14}{|c|}{ Elements at Risk } \\
\hline & & \multirow{2}{*}{\multicolumn{11}{|c|}{\begin{tabular}{l}
\multicolumn{2}{c}{ Structures and infrastructures } \\
Buildings
\end{tabular}}} & \multirow{2}{*}{\multicolumn{3}{|c|}{ Population }} \\
\hline & & & & \multicolumn{4}{|c|}{ Buildings } & \multicolumn{4}{|c|}{ Roads } & \multirow{2}{*}{$\begin{array}{c}\text { Others } \\
\text { Q }\end{array}$} & \multirow[b]{2}{*}{ Direct } & & \\
\hline & & $\mathrm{HD}$ & LD & IN & FA & SP & $\mathrm{C}$ & MR & SR & FR & RW & & & Indirect & Homeless \\
\hline \multirow{3}{*}{ Light } & Rock fall & A & $\mathrm{A}$ & A & A & A & A & A & A & A & A & $\mathrm{A}$ & No & No & No \\
\hline & Debris flow & A & A & A & A & A & A & A & $\mathrm{F}$ & $\mathrm{F}$ & A & A & No & No & No \\
\hline & Slide & A & A & A & A & A & A & A & $\mathrm{F}$ & $\mathrm{S}$ & A & A & No & No & No \\
\hline \multirow{3}{*}{ Medium } & Rock fall & $\mathrm{F}$ & $\mathrm{F}$ & $\mathrm{F}$ & $\mathrm{F}$ & $\mathrm{F}$ & $\mathrm{F}$ & $\mathrm{F}$ & $\mathrm{F}$ & $\mathrm{F}$ & $\mathrm{F}$ & $\mathrm{F}$ & Yes & Yes & Yes \\
\hline & Debris flow & $\mathrm{F}$ & $\mathrm{F}$ & $\mathrm{F}$ & $\mathrm{F}$ & $\mathrm{F}$ & $\mathrm{F}$ & $\mathrm{F}$ & $\mathrm{F}$ & $\mathrm{F}$ & $\mathrm{F}$ & $\mathrm{F}$ & Yes & Yes & Yes \\
\hline & Slide & $\mathrm{F}$ & $\mathrm{F}$ & $\mathrm{F}$ & $\mathrm{F}$ & $\mathrm{F}$ & $\mathrm{F}$ & $\mathrm{F}$ & $\mathrm{S}$ & $\mathrm{S}$ & $\mathrm{F}$ & $\mathrm{F}$ & No & Yes & No \\
\hline \multirow{3}{*}{ High } & Rock fall & $\mathrm{S}$ & $\mathrm{S}$ & $\mathrm{S}$ & $\mathrm{S}$ & $\mathrm{S}$ & $\mathrm{S}$ & $\mathrm{S}$ & $\mathrm{S}$ & $\mathrm{S}$ & $\mathrm{S}$ & $\mathrm{S}$ & Yes & Yes & Yes \\
\hline & Debris flow & $\mathrm{S}$ & $\mathrm{S}$ & $\mathrm{S}$ & $\mathrm{S}$ & $S$ & $\mathrm{~S}$ & $\mathrm{~S}$ & $\mathrm{~S}$ & $\mathrm{~S}$ & $\mathrm{~S}$ & $S$ & Yes & Yes & Yes \\
\hline & Slide & $\mathrm{S}$ & $\mathrm{S}$ & $\mathrm{S}$ & $\mathrm{S}$ & $\mathrm{S}$ & $\mathrm{S}$ & $\mathrm{S}$ & $\mathrm{S}$ & $\mathrm{S}$ & $\mathrm{S}$ & $S$ & No & Yes & Yes \\
\hline \multirow{3}{*}{ Very high } & Rock fall & S & S & $S$ & S & S & S & S & S & $S$ & S & $S$ & Yes & Yes & Yes \\
\hline & Debris flow & $\mathrm{S}$ & $\mathrm{S}$ & $\mathrm{S}$ & $\mathrm{S}$ & $\mathrm{S}$ & $\mathrm{S}$ & $\mathrm{S}$ & $\mathrm{S}$ & $\mathrm{S}$ & $S$ & $S$ & Yes & Yes & Yes \\
\hline & Slide & $\mathrm{S}$ & $\mathrm{S}$ & $\mathrm{S}$ & $\mathrm{S}$ & $\mathrm{S}$ & $\mathrm{S}$ & $\mathrm{S}$ & $\mathrm{S}$ & $\mathrm{S}$ & $S$ & $S$ & No & Yes & Yes \\
\hline
\end{tabular}

To estimate vulnerability we used a simple approach based on the inferred relationship between the intensity and type of the expected landslide, and the likely damage the landslide would cause. Table 5 shows the expected damage to buildings and roads, and to the population if (i.e. where) affected by landslides of different type (rock fall, debris flow or slide) and intensity (slight, medium, high, or very high). The latter is a function of landslide volume and velocity. Table 5 was prepared based on the review of the limited literature on the subject (Alexander, 1989; Michael-Leiba et al., 1999; Fell, 2000), the analysis of the damage caused by slope failures in Umbria (Felicioni et al., 1994, Alexander, 2000; Cardinali et al., 2000; Antonini et al., 2001), and our experience and judgement. A crude estimate (i.e. few, many, very many) of 
the number of people potentially subject to landslide risk was also considered.

Damage to structures and infrastructures was classified as:

- Superficial (aesthetic, minor) damage, where the functionality of buildings and roads is not compromised, and the damage can be repaired, rapidly and at low cost;

- Functional (medium) damage, where the functionality of structures or infrastructures is compromised, and the damage takes time and large resources to be fixed;

- Structural (severe or total) damage, where buildings or transportation routes are severely or completely damaged, and require extensive (and costly) work to be fixed. In this category, demolition and reconstruction may be required.

According to Table 5 a rock fall of light intensity is capable of causing superficial (minor) damage to buildings and roads; and a rock fall of high intensity (i.e. of larger volume) causes severe structural damage. A shallow slide of medium intensity causes aesthetic damage to buildings, functional damage to industrial and farming activities and to sport facilities, functional damage to major roads, and structural damage to other roads and railways. A deep-seated slide of very high intensity causes structural (i.e. severe) damage to all types of structures and infrastructures.

The expected damage to the population was classified as:

- Direct, where casualties are expected;

- Indirect, where only socio-economic damage is expected; and

- Temporary or permanent loss of private houses resulting in evacuees and homeless.

Direct damage to the population is foreseen for rapid and fast moving landslides, or for high intensity, slow moving ones. Indirect damage to the population is expected where landslides can cause functional or structural damage to the infrastructure, with negative socio-economic effects upon public facilities. Homelessness is expected where functional or structural damage to buildings is foreseen.

\section{Risk evaluation}

As previously discussed, a rigorous assessment of landslide risk is difficult to achieve. We argue that even where hazard and vulnerability cannot be determined as (numerical) probabilities, landslide risk still depends on the "state of nature" (i.e. landslide hazard, $H$ ) and on the expected damage (i.e. the vulnerability, $V$ ), or

$R_{s}=f(H, V)$.

We used this more general relationship to ascertain the specific landslide risk $\left(R_{S}\right)$, i.e. the risk to which a set of elements (e.g. building, roads, etc.) is subject when a landslide occurs (Einstein, 1988). We defined the specific risk separately for each class of elements at risk (Table 4), within each LHZ (Fig. 8).

To help assign a value of specific landslide risk to each element, we prepared Table 6. The table correlates the expected damage (i.e. aesthetic, functional or structural) to the landslide hazard. The latter was loosely ranked from low (11) to high (44) values. Construction of Table 6 required extensive discussion. It is largely based on the analysis of damage caused by two recent regional landslide events: a rapid snow melt that triggered thousands of failures in January 1997 (Cardinali et al., 2000), and the Umbria-Marche earthquakes of September-October 1997 that mostly caused rock falls (Antonini et al., 2001). Information on past landslide damage in the Umbria region was also considered ( $\mathrm{Fe}$ licioni et al., 1994; Alexander, 2000).

To show the level of specific risk, we added to the left of the two-digit landslide hazard index a third (alphanumerical) digit describing the expected damage (i.e. aesthetic, functional or structural, see Table 5). Thus, the specific risk index shows, from right to left, the landslide frequency, the landslide intensity, and the expected damage caused by the specific type of landslide (Table 6 and Fig. 8). If more than a single class of elements at risk is present in a LHZ, a different value of specific risk is computed for each class (e.g. Fig. 8b).

Figure 8 shows examples of specific landslide risk for various vulnerable elements in the Rotecastello area. Figure 8a shows that landslide risk for a major road (MR) is S14, because the expected damage is structural (S) and the hazard index is 14 (i.e. frequency is low and intensity is very high). In Fig. 8b landslide risk to a secondary road (SR) is defined as $\mathrm{S} 12$ because the expected damage is structural (S) and the hazard index is 12 (i.e. low frequency and medium intensity). In the same LHZ, landslide risk for the low-density settlement of Podere Piano (LD) is ascertained as A12, because the expected damage is superficial (A) and the hazard index is 12 . Figure $8 \mathrm{c}$ shows that landslide risk to a secondary road (SR) is F11, because the expected damage is functional (F) and the hazard index is low (i.e. 11 - low frequency and slight intensity). Lastly, Fig. 8d shows that landslide risk to the high-density settlement of Rotecastello (HD) is S33, because the expected damage is structural $(\mathrm{S})$ and the hazard index is 33, since both the landslide frequency and the landslide intensity are high.

As for the landslide hazard index, the landslide risk index $\left(R_{S}\right)$ does not provide an absolute ranking of risk levels. The "extreme" conditions are easily ranked: a house having an $R_{s}$ of A11 (i.e. aesthetic damage due to a low frequency and slight intensity slope failure) has a lower specific landslide risk than a dwelling with $R_{S}=\mathrm{S} 44$ (i.e. structural damage caused by a very high frequency and very high intensity landslide). It is not easy to decide for the several intermediate conditions. Decisions should be made on a case-by-case basis, considering the type of elements at risk, their vulner- 

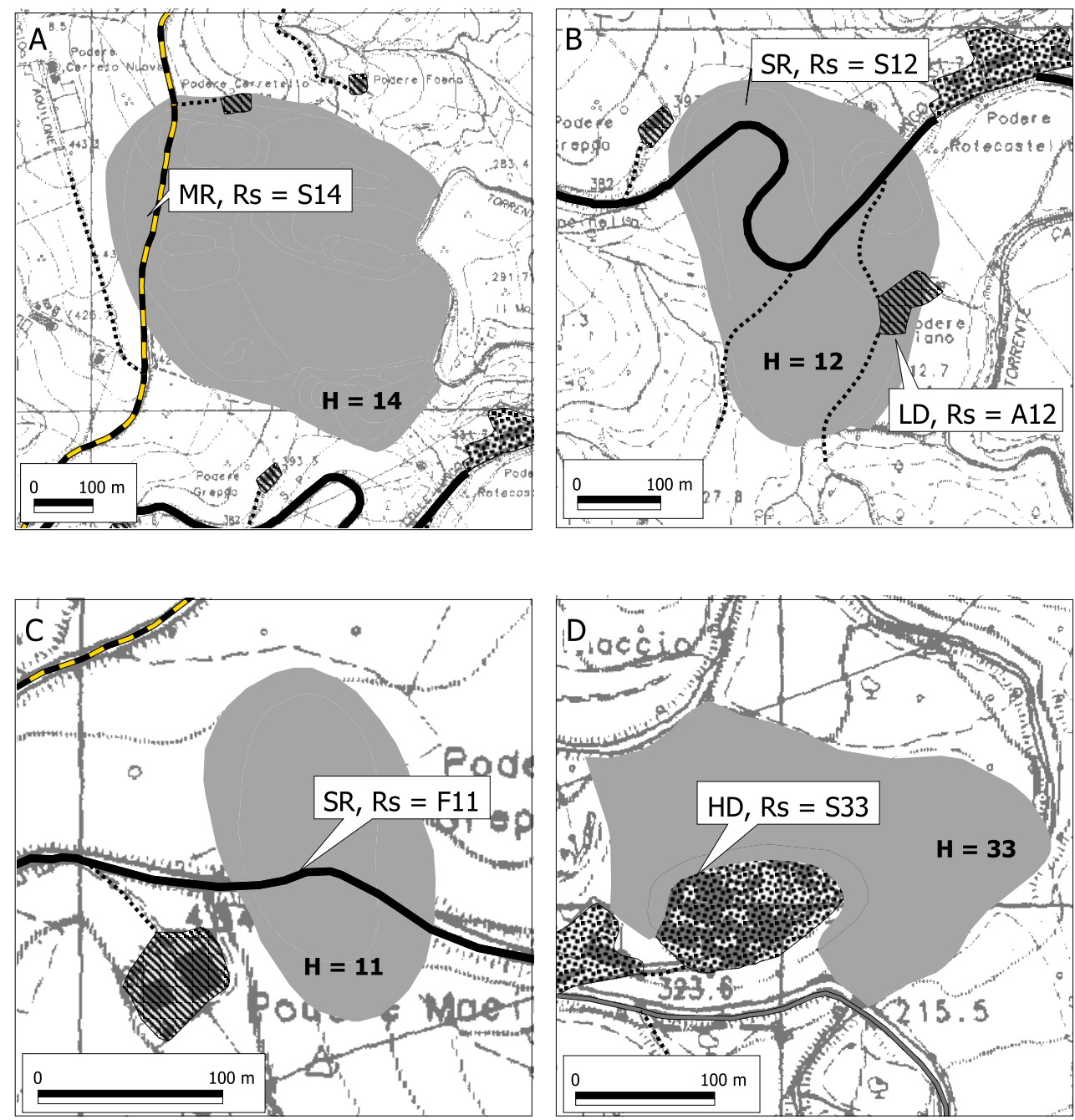

Fig. 8. Rotecastello, central Umbria. Maps of specific landslide risk (Rs). Grey pattern indicates the extent of the LHZ. (a) Landslide risk to a major road (MR). (b) Landslide risk to a secondary road (SR) and to a low-density settlement (LD). (c) Landslide risk to a secondary road (SR). (d) Landslide risk to the high-density settlement of Rotecastello (HD).

ability, the possible mitigation measures, and the economic and social implications of landslide risk.

Definition of specific landslide risk levels may not be enough where economic decisions must be taken. The Landslide Risk-Assessment and Reduction Act (Gazzetta Ufficiale della Repubblica Italiana, 1998) required the ranking of the most dangerous landslide areas according to the expected (total) landslide risk. Although we do not think that this is a wise way of dealing with landslide risk, we devised a system to aggregate the detailed information given by the specific landslide risk index into one of the four classes of landslide risk required by the law. Very high landslide risk (severe risk, R4) was assigned where rapid and fast-moving landslides could cause direct damage to the population. These were the areas where debris flows and rock falls could cause casualties or homelessness. High landslide risk (R3) was assigned to the areas where slow-moving landslides could cause structural and functional damage to structures and infrastructure.
In these areas casualties are not expected. Moderate landslide risk (R2) was attributed where aesthetic damage to vulnerable elements is expected, caused by slow-moving slope failures by fast or rapid moving landslides of slight intensity. Lastly, low landslide risk (R1) was assigned to the areas where no element at risk is currently present within a landslide hazard zone.

\section{Discussion}

At the 79 study areas considered in this work we identified 980 landslide hazard zones (LHZ), pertaining to all the lithological complexes and major landform types present in Umbria (Fig. 1). Due to funding and time constraints, landslide risk was ascertained for a subset of $210 \mathrm{LHZ}$ (21.4\%), covering a total of about $20 \mathrm{~km}^{2}$. The data set is large enough to enable some general conclusions to be drawn. 
Table 6. Levels of specific landslide risk, based on landslide hazard, in 16 classes (see Table 3), and vulnerability, in 3 classes (see Table 5). Classes of specific risk assigned to the 79 study areas are shown in bold type

\begin{tabular}{|c|c|c|c|c|}
\hline \multicolumn{2}{|c|}{ Hazard } & \multicolumn{3}{|c|}{ Vulnerability (expected damage) } \\
\hline & & (Minor) damage & (Major) damage & (Total) damage \\
\hline & 11 & A 11 & F 11 & S 11 \\
\hline & 12 & A 12 & F 12 & S 12 \\
\hline low & 13 & A 13 & F 13 & S 13 \\
\hline \multirow{9}{*}{$\uparrow$} & 21 & A 21 & F 21 & S 21 \\
\hline & 14 & A 14 & F 14 & S 14 \\
\hline & 22 & A 22 & F 22 & S 22 \\
\hline & 23 & A 23 & F 23 & S 23 \\
\hline & 31 & A 31 & F 31 & S 31 \\
\hline & 32 & A 32 & F 32 & S 32 \\
\hline & 24 & A 24 & F 24 & S 24 \\
\hline & 33 & A 33 & F 33 & S 33 \\
\hline & 41 & A 41 & F 41 & S 41 \\
\hline$\downarrow$ & 42 & A 42 & F 42 & S 42 \\
\hline \multirow[t]{3}{*}{ high } & 34 & A 34 & F 34 & S 34 \\
\hline & 43 & A 43 & F 43 & S 43 \\
\hline & 44 & A 44 & F 44 & S 44 \\
\hline
\end{tabular}

The proposed geomorphological method is empirical and subject to various levels of uncertainty, but has proved to be reliable and cost effective, allowing for a detailed definition of landslide hazard and risk in urban and rural areas. The method allows for the comparison of landslide hazard and risk in different (and distant) areas, and where different landslide types are present.

Assessment of landslide hazard requires forecasts to be made in different settings in space and time, and with different types and dimensions. It can be carried out over a large area, such as a drainage basin or province, or for a single landslide or group of landslides (Cruden and Fell, 1997; Guzzetti et al., 1999). The proposed method ascertains landslide hazard in the areas of (probable) evolution of the existing landslides, and for the various types of failures (i.e. slides, debris flows, rock falls) separately. The method says nothing about the hazard outside a LHZ, even within the same elementary slope. In these areas minor landslides, mostly superficial failures can occur with a low frequency. For a regional, spatially distributed landslide hazard and risk assessment, other methods should be used (van Westen, 1994; Carrara et al., 1995, 1999; Guzzetti et al., 1999), possibly in combination with the method proposed here.

The methodology requires extensive geomorphological judgment. For this reason it should only be used by skilled geomorphologists. If the extent, type, distribution and pattern of past and present landslides are not correctly and fully identified, serious errors can occur and thus affect the estimate of landslide hazard and risk.

With this in mind, the definition of the temporal frequency of landslides from the analysis of the multi-temporal inventory map is particularly important. The map covers a period of 60 years (1941-2001), which is long enough to evaluate the short-term evolution of slopes in the areas investigated.
Where information on landslide frequency is available for a shorter period of time (10-15 years or less), the reliability of the hazard forecast is reduced. If a landslide event fails to be recognized, the frequency of occurrence is underestimated, and hazard and risk estimates are negatively affected. It should be noted that the method estimates the expected landslide frequency based on what has happened (and was observed) in the recent past. If low frequency, high magnitude events did not occur (or were not recognised) in a LHZ, the hazard assessment in the area may be biased, and the actual risk underestimated. This is a limitation of the method.

Uncertainty varies with the different steps of the method. The production of both the separate landslide inventory maps, and the (combined) multi-temporal landslide map was less uncertain than the identification of the landslide hazard zones, or the possible spatial evolution of the existing landslides, which were obtained mostly through geomorphological inference. Landslides mapped through the interpretation of aerial photographs were carefully checked in the field, whereas the identification and mapping of LHZs was based on the observation of other landslides and on the inferred geomorphological evolution of slopes. Estimates of landslide volume and velocity, which are essential for the evaluation of landslide intensity, also exhibited uncertainty.

The method relies on correlation tables, which are used to define landslide intensity (Table 2), ascertain landslide hazard (Table 3), evaluate the expected damage to the vulnerable elements (Table 5), and estimate landslide risk (Table 6). These tables are based on empirical observations and on our own experience, but are also the result of a heuristic approach. Whenever possible, we tried several possibilities and evaluated the difference after each attempt. We believe that the tables fit the present understanding of landslide processes and match landslide damage in Umbria satisfactorily.

However, the tables should not be considered definitive 
and should not be used unconditionally in all settings. If applied to other sites, or in other study areas, the tables should be carefully checked with the local information on landslide types and damage. If one or more of the tables is changed significantly, the hazard and risk assessment will vary, and may not be comparable to the one we have prepared. This is particularly important for Tables 5 and 6 .

Landslide hazard and risk are expressed using a multipledigit index that portrays, in a compact format, all the variables used to ascertain landslide hazard and risk. The index allows for the ranking of risk conditions at the end of the risk assessment process, when all the necessary information is available, and not "a priori", based on pre-defined categories. We consider this a major advantage of the method, giving decision makers great flexibility in deciding which area exhibits the highest risk, and providing geologists and engineers with a clue about why any given vulnerable element is at risk.

Lastly, the proposed method is not simple. For a dependable and consistent prediction it requires multiple sets of aerial photographs, and a team of experienced geomorphologists to interpret them. This cannot be considered a limitation: landslide hazard and risk assessments are difficult tasks, and require proper expertise and skills.

\section{Conclusions}

We have presented a geomorphological method to ascertain landslide hazard and to evaluate the associated risk in the Umbria Region. The method is based on careful recognition of present and past landslides, scrutiny of the local geological and morphological settings, and analysis of site-specific and historical information on past landslide events. Most of the information used to ascertain landslide hazard is obtained from the careful analysis of a multi-temporal landslide inventory map that portrays information on the distribution, type and pattern of landslides, and on their changes in time. The resulting map is obtained by merging landslide inventory maps prepared through the analysis of stereoscopic aerial photographs of different ages, together with field surveys.

The method was applied in 210 landslide hazard zones located around or in the vicinity of 79 towns and villages in the Umbria Region. In these areas landslide hazard was ascertained, vulnerable elements were identified, and specific risk was evaluated. The results prove that, although it is empirical and subject to various levels of uncertainty, the method can provide reasonable estimates of landslide hazards and risk in urban and rural areas. At present it is not possible to judge quantitatively how good the proposed method is. Reliability and effectiveness of the maps will have to be evaluated by Town Officials, private consultants involved in land use and city planning, and other impartial observers. The time and human resources required for completing the risk assessment procedure at each site averaged 5 days for a team of 3-4 people, including bibliographical investigation, interpretation of the aerial photographs, field surveys, and the production of the final maps in digital format.

Acknowledgements. The research was supported by grants from the Regione dell'Umbria and the Tiber River Basin Authority. We are grateful to D. Alexander and E. Brabb for reviewing the manuscript. This paper is CNR-GNDCI publication number 2458.

\section{References}

Alexander, D.: Urban landslides, Progress in Physical Geography, 13, 2, 157-191, 1989.

Alexander, D.: Landslide risk estimation in Umbria Region. Unpublished technical report for the CNR-IRPI, 110, 2000.

Antonini, G., Ardizzone, F., Cardinali, M., Galli, M., Guzzetti, F., and Reichenbach, P.: Surface deposits and landslide inventory map of the area affected by the 1997 Umbria-Marche earthquakes. Bollettino Societá Geologica Italiana, in press, 2001.

Cardinali, M., Ardizzone, F., Galli, M., Guzzetti, F., and Reichenbach, P.: Landslides triggered by rapid snow melting: the December 1996-January 1997 event in Central Italy. Claps P. and Siccardi F. (eds.), Mediterranean Storms, Proceedings Plinius Conference'99, Maratea, 14-16 October 1999, CNR GNDCI publication number 2012. Bios, Cosenza, 439-448, 2000.

Cardinali, M., Antonini, G., Reichenbach, P., and Guzzetti, F.: Photo-geological and landslide inventory map of the Upper Tiber River basin. CNR GNDCI publication number 2154, map at 1:100 000 scale, 2001.

Carrara, A., Cardinali, M., Guzzetti, F., and Reichenbach, P.: GIS technology in mapping landslide hazard. In: Carrara, A. and Guzzetti, F. (eds.), Geographical Information Systems in Assessing Natural Hazards. Kluwer Academic Publisher, Dordrecht, The Netherlands, 135-175, 1995.

Carrara, A., Guzzetti, F., Cardinali, M., and Reichenbach, P.: Use of GIS Technology in the Prediction and Monitoring of Landslide Hazard. In: Carrara, A. and Guzzetti, F. (eds.), Natural Hazards, special issue on Techniques and Tools for Mapping Natural Hazards and Risk Impact on the Developed Environment, 20, 2-3, 117-135, 1999.

Catenacci, V.: Il dissesto geologico e geoambientale in Italia dal dopoguerra al 1990. Memorie Descrittive della Carta Geologica d'Italia, Servizio Geologico Nazionale, (in Italian), 47, 301, 1992.

Crescenti, U.: La grande frana di Ancona del 13 dicembre 1982. Studi Geologici Camerti, Special Issue, Camerino, (in Italian), 1, 1986.

Cruden, D. M. and Fell, R. (eds.): Landslide risk assessment. Proceedings International Workshop on Landslide Risk Assessment, Honolulu, 19-21 February 1997, Balkema, Rotterdam, 371, 1997.

Cruden, D. M. and Varnes, D. J.: Landslide types and processes. In: Turner, A. K. and Schuster, R. L. (eds.), Landslides, Investigation and Mitigation. Transportation Research Board, Special Report 247, Washington D. C., 36-75, 1996.

Einstein, H. H.: Special lecture: Landslide risk assessment procedure. Proceedings 5th International Symposium on Landslides, Lausanne, 2, 1075-1090, 1988.

Einstein, H. H.: Landslide Risk - Systematic approaches to assessment and management. In: Cruden, D. M. and Fell, R. (eds.), Landslide Risk Assessment. Proceedings International Work- 
shop on Landslide Risk Assessment, Honolulu, 19-21 February 1997, Balkema, Rotterdam, 25-50, 1997.

Fell, R.: Landslide risk assessment and acceptable risk. Canadian Geotechnical Journal. 32, 2, 261-272, 1994.

Fell, R. and Hartford, D.: Landslide risk management. In: Cruden, D. and Fell, R. (eds.), Proceedings International Workshop on Landslide Risk Assessment, Honolulu, 19-21 February 1997, Balkema, Rotterdam, 51-109, 1997.

Fell, R.: Landslide risk management concepts and guidelines. Australian Geomechanics Society, Sub-committee on landslide risk management, 69, 2000.

Felicioni, G., Martini, E., and Ribaldi, C.: Studio dei Centri Abitati Instabili in Umbria. Atlante regionale: CNR GNDCI publication number 979, Rubettino Publisher, (in Italian), 418, 1994.

Gazzetta Ufficiale della Repubblica Italiana: Misure urgenti per la prevenzione del rischio idrogeologico ed a favore delle zone colpite da disastri franosi nella regione Campania. Serie Generale, Anno 139, n. 208, 7 September 1998, (in Italian), 53-74, 1998.

Gazzetta Ufficiale della Repubblica Italiana: Atto di indirizzo e coordinamento per l'individuazione dei criteri relativi agli adempimenti di cui all'art. 1, commi 1 e 2, del decreto-legge 11 giugno 1998, n. 180. Serie Generale, Anno 140, n. 3, 5 January 1999, (in Italian), 8-34, 1999.

Glade, T.: Establishing the frequency and magnitude of landslidetriggering rainstorm events in New Zealand. Environmental Geology, 35, 2-3, 160-174, 1998.

Guzzetti, F.: Landslide fatalities and evaluation of landslide risk in Italy, Engineering Geology, 58, 89-107, 2000.

Guzzetti, F. and Cardinali, M.: Carta Inventario dei Fenomeni Franosi della Regione dell'Umbria ed aree limitrofe. CNR GNDCI publication number 204, 2 sheets, scale 1:100000, (in Italian, 1989.

Guzzetti, F., Cardinali, M., and Reichenbach, P.: The influence of structural setting and lithology on landslide type and pattern. Environmental and Engineering Geoscience, 2, 4, 531-555, 1996.

Guzzetti, F., Carrara, A., Cardinali, M., and Reichenbach, P.: Landslide hazard evaluation: an aid to a sustainable development. Geomorphology, 31, 181-216, 1999.

Hungr, O.: Some methods of landslide hazard intensity mapping. In Cruden, D. M. and Fell, R., (eds.), Landslide risk assessment.
Proceedings International Workshop on Landslide Risk Assessment, Honolulu, 19-21 February 1997, Balkema, Rotterdam, 215-226, 1997.

Hutchinson, J. N.: Keynote paper: Landslide hazard assessment. In: Bell (ed.), Landslides, Balkema, Rotterdam, 1805-1841, 1995.

Ibsen, M.L. and Brunsden, D.: The nature, use and problems of historical archives for the temporal occurrence of landslides, with specific reference to the south coast of Britain, Ventnor, Isle of Wight, Geomorphology, 15, 241-258, 1996.

Michael-Leiba, M., Baynes, F., and Scott, G.: Quantitative landslides of Cains. Australian Geological Survey Organisation, Department of Industry, Science \& Resources. AGSO Records 1999/36, 40, 1999.

Regione Piemonte: Eventi Alluvionali in Piemonte. 2-6 novembre 1994, 8 luglio 1996, 7-10 ottobre 1996. Direzione Servizi Tecnici di Prevenzione, Torino, (in Italian), 415, 1998.

Servizio Geologico d'Italia: Carta Geologica dell'Umbria. Map at 1:250 000 scale, (in Italian), 1980.

van Westen, C. J.: GIS in landslide hazard zonation: A review with examples from the Colombian Andes. In: Price, M. F. and Heywood, D. I. (eds.), Taylor and Francis, London, 135-165, 1994.

Varnes, D. J.: Slope movements, type and processes. In: Schuster, R.L. and Krizek, R.J. (eds.), Landslide analysis and control Transportation Research Board, National Academy Sciences, Washington, D. C., Special report 176, 11-33, 1978.

Varnes, D. J. and IAEG Commission on Landslides and other MassMovements: Landslide hazard zonation: a review of principles and practice. UNESCO Press, Paris, 63, 1984.

WP/WLI - International Geotechnical societies' UNESCO Working Party on World Landslide Inventory: A suggested method for reporting a landslide. International Association Engineering Geology Bulletin, 41, 5-12, 1990.

WP/WLI - International Geotechnical societies' UNESCO Working Party on World Landslide Inventory: A suggested method for describing the activity of a landslide. International Association Engineering Geology Bulletin, 47, 53-57, 1993.

WP/WLI - International Geotechnical societies' UNESCO Working Party on World Landslide Inventory: A suggested method for describing the rate of movement of a landslide. International Association Engineering Geology Bulletin, 52, 75-78, 1995. 